\title{
Narrative and the Language Use Maturity Index: A Non-Concurrent Multiple-Baseline Design on Adult English Language Learners
}

\author{
Sepideh Yasrebi ${ }^{1}$ \\ ${ }^{1}$ University at Albany, New York, USA \\ Correspondence: Sepideh Yasrebi, University at Albany, New York, USA \\ Email: syasrebi@albany.edu
}

Received: June 21, $2019 \quad$ Accepted: August 27, $2019 \quad$ Online Published: September 1, 2019

doi: 10.23918/ijsses.v6i1p49

\begin{abstract}
This single-subject study, aims at tracing English as a New Language (ENL) learners' attempts in articulating their thoughts in syntactically, semantically and pragmatically mature ways in their L2 writings. While most studies in SLA have explored syntactic maturity developments among native speakers, the current study claims that all three (syntactic, semantic, and pragmatic) elements of language use are equally important. This study seeks to explore two main research questions: (1) To what extent does the implementation of the narrative form in creating writing tasks constitute a change in language use maturity index of the ENL adult learners in diagnostic phases? (2) What general semantic, syntactic and pragmatic patterns emerge during each phase? A non-concurrent multiple-baseline design (MBD) is employed to examine the results of narrative-based assessments on language use maturity index of ENL adult learners. Four ENL adult learners with a mean score of 6 in their IELTS writing skill were selected to complete the writing tasks during the baseline and the three treatment phases. Overall 56 written tasks were collected from all the participants. Visual analyses were conducted, along with estimated effect sizes using quantitative methods at both the individual level and across cases. Visual analyses revealed evidence for a functional relationship between the narrative-based assessment tool and the ENLs' language use maturity index. Quantitatively, very large effects were noted for all the participants. Anecdotal evidence suggested that narrative as a linguistic form negates any merely unilateral (either bottom-up or top-down), fragmentary approach, but rather foregrounds the necessity for both vertical and horizontal movements, both syntagmatic and paradigmatic, both retrospective and anticipatory, both subjective and objective relations and finally both the registers of form and content in language use. We suggest that these grammatical aspects of dialogue are inescapably intertwined with literary style of narrative. Movement (development), then, rather than stasis, time rather than space, knowledge rather than information constitutes some aspects of the modality of narrative, and it is in this sense that this last must be understood as our optimum pedagogical form. Implementing narratives in classrooms can make for a culturally responsive pedagogy and it should be practiced and promoted in K-12 classrooms. Results suggest that the strategy has potential to improve the language use maturity index with ENL learners.
\end{abstract}

Keywords: English as a New Language (ENL), Syntactic Maturity, Semantic Maturity, Pragmatic Maturity, Language Use Maturity Index, Multiple-Baseline Design (MBD)

\section{Rationale and Objective of the Study}

K-12 content area and the English as a New Language (ENL hereafter) teachers' increasing involvement in supporting ENLs' writing and reading skills (August, McCardle, \& Shanahan, 2014) on the one hand, and poor academic performance on state tests (e.g., U.S. Department of Education, Institute of Education Sciences, National Center for Education Statistics, 2015) on the other, have motivated the author to 
conduct the current research. This situation underscores the need for evidence-based interventions (EBIs) validated for ENL youth (Moore \& Klingner, 2014). The current study then will examine the syntactic, semantic and pragmatic conditions of possibility of language use maturity among ENLs. The impulse behind this project is therefore diagnostic: it strives to detect and identify the causal relationships (if any) that prevent ENLs from composing and utilizing syntactically, semantically and pragmatically mature elements in their writing products. Furthermore, the non-concurrent Multiple Baseline Design (MBD hereafter) will allow us to analyze the baseline trend of the ENL participants to identify the core characteristics of their initial attempts before the diagnostic phases start. The baseline trend represents the learners' attempts in classroom settings where no diagnostic task is being implemented and where students are being introduced to daily language practices. The purpose of the baseline trend is twofold: (1) to document a pattern of behavior in need of change; (2) to document a pattern that has a sufficiently consistent level and variability, with little or no trend, so as to allow comparison with a new pattern following the diagnostic or treatment phases.

This study should be understood as an attempt to respond to the following two major research questions: (1) To what extent does the implementation of the narrative form in creating writing tasks constitute a change in language use maturity index of the ENL adult learners in diagnostic phases? (2) And, what general semantic, syntactic and pragmatic patterns emerge during each phase?

Several studies (Atanassova, 2001, Weist et al., 1999) focusing primarily on native speakers' languagecognition relationship have revealed the influence of various language tasks on complex-sentence production. Whereas most studies have explored syntactic maturity developments among native speakers, the current study claims that all three (syntactic, semantic, and pragmatic) elements of language use are equally important. For the methodological purposes of this study, I have designed a language use maturity index (see Figure 1) to analyze data (we shall return to this shortly). The tasks designed in this study range from constrained to free in terms of the degree to which external limits are put on ENLs' cognitive skills. The implementation of such specific cognitive tasks will then be shown to validate our hypothesis that the former have substantial effects in the escalation of language use maturity. Our goal here will be to identify and analyze those linguistic elements which are syntactically, semantically and pragmatically associated with language use maturity, and to address a gap in recent scholarship which, as mentioned above, has ignored the significance of this issue in the case of ENLs in K-12 settings.

\section{Toward a Formulation of Language Use Maturity}

Writing is a multidimensional process that involves syntactic, semantic, pragmatic and audience awareness (Lesaux, Koda, Siegel, \& Shanahan 2006; Roth, 2000). Here we will explore the relevant literature in SLA with regard to language maturity: it will become clear to the reader that such maturity has been almost always framed in terms of syntactic maturity, with some exceptions bringing in the register of semantics into the fold as well. After reviewing the relevant research, we will then set out to formulate what we mean by "Language Use Maturity Index" within the framework of the current study.

Syntactic maturity is broadly understood in educational settings as the range and the sophistication of grammatical resources learners exhibit during language production (Ortega, 2015). What is often ignored, however, is that far from being a fixed, static concept, syntactic maturity constitutes a dependent variable and as such should be examined as the specific quality of language production which is structurally 
contingent on and is a function of other forces (age, L1 literacy level, access to quality education etc.). Syntactic maturity, as it manifests itself in learners' writing modality, is thus understood here as symptomatic of a more general trajectory of linguistic development. In other words, our operative assumption is that syntactic maturity indexes the expansion of the capacity to use language in more complex and skillful ways, drawing on the full range of linguistic resources in order to fulfill various communicative goals efficiently. Yet syntactic maturity continues to remain a fuzzy term and concept for which no clear measurements have so far been obtained so as to evaluate and map out its development. At the same time, and despite this shortcoming, it seems to be inherently overdetermined. That is, syntactic maturity is a necessary yet not sufficient means for the ENLs to reach the ultimate goal, namely, language use maturity. Grammar contains facts and rules about the given language system that must be followed (at least to some extent) otherwise the language is unrecognizable. So one can deduce that syntactic maturity is more bound to correctness of syntactical forms. It is important to note that syntactic maturity has mostly been studied in relation to successful usage of syntactically complex structures in L2 writing. While writing is a social activity that can happen almost everywhere in our lives, the bulk of L2 writing research is limited to educational and academic contexts. The implication of this type of research is unmistakable: the learner will become more syntactically mature insofar as they are exposed to formal, institutional education. It has been adequately demonstrated that a learner's syntactical maturation is overdetermined by a variety of internal and external factors, i.e., psychological, socioeconomic, cultural and so on. Vygotsky (1978), for instance, characterized a child's intellectual development as one that "never follows school learning the way a shadow follows the object that casts it" (p. 91). That is to say, one's formal education and intellectual development seem to be no necessarily commensurate.

Cooper et al. (1980), however, look at the situation differently. They argue that writing skills can be systematically taught, and that development can be accelerated through the use of certain grammatical exercises, especially sentence combining exercises. Strong (1985), conversely, claims that simply adding more complex structures to a sentence is little more than sentence manipulation. Rather than the outer, physiological game of writing, Strong believes in the automaticity in the inner and the psychological, whereby students are allowed to self-direct themselves to the basics of syntax. He draws attention, on that account, to the fact that automaticity - fundamental as it is to meaning-making — cannot be directly taught. It is rather a set of psycholinguistic processes that each person must internalize independently of wellintentioned instruction. Automaticity with print is built up from within, and it is the key to language use maturity. Yet we are not in a position to realize the degree to which such an injunction may prove problematic: by retreating to the sphere of interiority, Strong seems to be evacuating language use maturity, or language as such, of its socio-cultural determinants: that is to say, by conceiving automaticity in purely subjective terms, he ultimately separates parole from the register of langue, thereby exposing himself, it seems to me, to the charge of psychologism.

What is at issue here is that syntactic maturity in and of itself is not an adequate index of learners' language use maturity. I argue that the domains of semantic, syntactic and pragmatic maturity are inextricably intertwined to the extent that one cannot theorize the complex issue of language use maturity without addressing all three spheres: semantics, syntax and pragmatics. So semantic knowledge cannot be ignored when we look at the language use maturity of learners. Semantics and vocabulary knowledge are defined by Isaacson (1988) as the originality and the maturity of a learner's choice of words. The development of a rich and varied vocabulary is considered an essential step in becoming an effective writer (Baker, Gersten 
\& Graham, 2003; Roth, 2000). Although accurate choice of vocabulary items is important, I would argue that, for the reasons I will explain below, defining semantic maturity in the terms set by Isaacson is unsatisfactory. Halliday (1985), for instance, views semantic development of the learners equally important as the syntactic ones, which he aptly frames as the lexico-grammatical resource. This is important for it has the major consequence of building noun-centered rather than verb-centered syntax, the semantic implication of which carries meaning that spills over the sentence level and into the whole discourse. Halliday's (1973) and Halliday and Hasan's (1976) argue that conceptualization of the linguistic system places heavy emphasis on the sociocultural context that mediates meaning in language use situations.

Similarly, Canale and Swain (1980) refer to this mediation as "meaning potential approach to language" (p. 18). Nattinger and DeCarrico take this one step further and suggest that much of the language we use is made of prefabricated chunks into which different lexical items can be slotted (1992, p.182). Additionally, Lakoff and Johnson (1980, p. 28) argue that our conceptual system is "fundamentally metaphorical in nature," which is reflected in our everyday language by a wide variety of expressions and vocabulary. Understanding figurative language involves a process of inference, which, as scholars have pointed out, requires an act of "completion" on the part of the reader, who establishes a "linkage" between the two disparate elements being compared, and makes a series of linguistic inferences (Nowottny, 1962, p. 59).

Inasmuch as a human being's conceptual system is inherently metaphorical, it follows then that our ability in general, and ENLs in particular, to identify, comprehend and mobilize figurative language constitutes a crucial component in achieving semantic maturity. On the other hand, people who belong to a certain speech community have preferred ways of saying things (Wray 1999; Kecskes, 2007) and preferred ways of organizing thoughts (Kecskes, 2007, 2013), which foreground pragmatic concerns: "preferred ways of saying things are generally reflected in the use of formulaic language and figurative language, while preferred ways of organizing thoughts can be detected through, for instance, the use of subordinate conjunctions, clauses and discourse markers. Selecting the right words and expressions and formulating utterances in ways preferred by native speakers of that language is more important than syntax" (Kecskes, 2016, p.8). Although not all formulaic language is figurative, it seems to me that what is at stake here is then the way in which syntactic and semantic knowledge are inextricably linked to pragmatic competence. This last can also be explained through its economizing role in speech production (Miller \& Weinert 1998; Wray 1999). In communication, that is to say, speakers generally seek to achieve more cognitive effect with less processing effect (economy of language), which is also characteristic of metaphorical or figurative language use: hence the significance of pragmatic concerns and maturity with regards to ENL learners.

Grammatical maturity and semantic maturity must always be considered in conjunction with individual's sociolinguistic and discourse competence: that is, pragmatic maturity. We thus argue that pragmatic maturity (the appropriateness of language use) constitutes a crucial component of our overall language use maturity index: pragmatic maturity is tied to grammatical knowledge (Bachman \& Palmer, 1996), and they are closely interdependent. As Kecskes observes regarding pragmatic rules: "not following them may cause misinterpretation of linguistic behavior and many different reactions from the hearers. If grammar is bad, the utterance may not convey the right message or any message while if pragmatics is bad, the 
utterance will usually convey the wrong message" $(2015$, p. 3$)$. What is at stake here is therefore not simply the speaker's syntactical or semantic choices as such but rather the way in which the positionality and spatiotemporal situatedness of speaker-hearer determines the specificity and availability of those choices in the first place: this last then constitutes a structural limit, at any given moment, on the quantity of syntagmatic and paradigmatic options of combination and substitution in the meaning making process. This is also what Hymes (1972) had in mind when he underscored the need of L2 learners to become communicatively competent for a given social context. Pragmatics then has been recognized as an essential aspect of communicative competence (Canale, 1983; Canale \& Swain, 1980).

For the methodological purposes of this study, we have defined a continuum, that is, Language Use Maturity Index, which consists of nine constituents (see Figure 1). Here, constituents one to four (word class, clausal forms, comparatives, cohesive devices) mark syntactic maturity in L2 language use. Constituents five to seven (word order, connotations, figurative language) mainly demonstrate semantic maturity in L2 language use. And constituents eight and nine (reasoning and tone) reflect the pragmatic maturity. Our proposed continuum is a measurement tool and developmental tool at the same time. It is important to highlight that we keep the trichotomy (that is syntactic, semantic, and pragmatic) merely for the analytic reasons, but these three domains are intertwined. Furthermore, the continuum is utilized as an evaluative measure, and that assessing the "correct" use of these constituents is irrelevant in this study. Any attempts by the learners that reflect developments of constituents 1-9 is taken as a sign of language use maturity. In short, we are interested in what triggers the development of these constituents in the written products of our participants and the way in which they can be maintained.

(2) use of clauses: independent, dependent, noun, relative, adverbial
(3) ability to incorporate comparative syntactic elements
(4) use of appropriate and varied transitions and syntax to link major sections.
(5) use of patterns of word changes indicating different word classes (word order)
(6) apprehending connotations and denotations
(7) applying figurative language based on the situational context of the texts
(8) establishing claims, counterclaims, valid reasoning, and evidence
(9) establishing and maintaining a formal style and objective tone

Figure 1: Language Use Maturity Index

There have been numerous studies on promoting syntactic maturity of learners, and a few on semantic and pragmatic maturity of native speakers, but there is scarcely any substantial relevant literature that examines language use maturity in the field of ENL studies. It is thus important to understand how and what kinds of syntactically complex structures contribute to improving writing modality as reflected in higher ratings of text quality for both developmental and educational perspectives. A broadening of the agenda, however, 
seems worthwhile for future research: how can all the three main elements of language use maturity (syntactic, semantic and pragmatic) be developed in ENL and content area classroom in K-12?

\section{Setting}

The current study was conducted at the Intensive English Language Program department (IELP hereafter) at UAlbany. Participants included four international students - two males and two females - who were all between 19 to 21 years old. All the participants were enrolled in IELP program to improve their academic English language skills.

\section{Participants}

Sarah:

A 19-year-old, first-year, Bengali international exchange student at UAlbany, Sarah moved to NY state at the beginning of the 2017-2018 academic year. Her records show that her total academic IELTS score was 5.5, and her reading and writing scores were respectively 5, and 5.5.

\section{Zheng:}

Zheng was a 20 -year-old Chinese international exchange student at UAlbany. He came to the school at the beginning of the 2017-2018 academic school year. Zheng's total academic IELTS score was 6, and his reading and writing scores were respectively 6 , and 5.5 .

Zayed:

Zayed was a 21-year-old Indian international exchange student at UAlbany. He came to the school at the beginning of the 2017-2018 academic year. His total academic IELTS score was 6.5, and his reading and writing scores were respectively 6.5 , and 5.5 .

Maria:

Maria was a 20-year old, Latina international exchange student at UAlbany. She was in her second year of college at the school. She was born in Columbia, and previously attended a bilingual school in her home country. Maria's total grade in the IELTS exam was 6, and her reading and writing scores were respectively 6 , and 6 .

\section{Experimental Design and Materials}

A Multiple Baseline Design (MBD) (Gast, 2010) was selected to document changes in participants' language maturity index from baseline to treatment phases A, B and C. This method was selected because it has proven to be effective in previous single-subject studies on teaching writing to students with EBDs (e.g., Mastropieri et al., 2009). Data analyses followed the What Works Clearinghouse (WWC) singlecase design guidelines for evaluating treatment effects (Kratochwill et al., 2013). Following the baseline phase - which included the collection of five writing tasks from each participant during the course of their classes at IELP - three treatment phases were implemented non-concurrently for each participant. It is important to reiterate that all treatment phases were replicated three times for each participant and that 
overall 14 tasks were collected from each participant. The three treatment phases conducted in this study are as follows:

1. The first treatment phase (Treatment A) was the most constrained one in terms of narrowing down the scope of the participant's cognitive ability: here, the participants were asked to read a text and then re-formulate its content in the form of a written narrative. Each participant was provided with a keyword sheet consisting of several semantic and syntactic utterances extracted directly from the text as linguistic support to help them to reformulate the content of the narrative task. Whether or not to use those utterances in their narrative was at the discretion of the participants. The utterances were provided to assist the learners to re-formulate the text in a logical chronological flow (see appendix B for the samples of treatments A, B and C).

2. The second treatment phase (Treatment B) was a less constrained task in comparison to the first treatment phase: here, the participants were required to read a different text and re-formulate its content in the form of a written narrative. This time, however, the participants were provided with a supplementary sheet consisted of several synonymous semantic and syntactic utterances designed to assist the learners in the process of reformulation of the text. In this treatment phase, the participants had to rely more on their own memory in the process of reformulation of the narrative. The synonymous semantic and syntactic utterances were designed to help the participants remember the content of the text in modified forms. The synonymous constructions were not given in a chronological order.

3. Finally, in the third treatment phase (Treatment C), framed as a free task, each participant was given a photo as a visual support and was asked to narrate their own stories. This task is considered to be the most creative task of all, in which the participants were allowed to rely on their own linguistic resources to develop a narrative which was scaffolded by a visual support.

As explained above, for the first two treatment phases, reading and writing tasks were combined because it is also impossible to review the research history of writing development without addressing the relationships between reading and writing. The connection between reading and writing has been wellestablished by correlational and cross-sectional studies (Ehri, 1989; Juel, 1988; Juel, Griffith, \& Gough, 1985; Shanahan, 1984), which warrants our approach in combining reading and writing tasks for our first two diagnostic phases.

\section{Treatment Fidelity}

Two steps were practiced to assess treatment fidelity: first, the researcher followed a written directive for all three treatment phases and provided all participants with a written instruction followed by oral directives; second, all data collection sessions were tape-recorded. $50 \%$ of the tapes were randomly selected for review by a $\mathrm{PhD}$ student in the ETAP Department, who double-checked the written instructions. The review indicated that $98 \%$ of the steps were followed with precision, which meets WWC standards (Kratochwill et al., 2013); while other steps were followed with minimal modifications. These modifications included minimal changes in oral explanations of the tasks. 


\section{Data Analyses}

Data analyses in this study were followed by WWC guidelines and performed in three stages: (1) visual analysis; (2) across-case effect sizes; (3) multilevel modeling. We shall discuss each stage in more details under the "results" section. Visual analyses were conducted to determine if there was a functional relationship between the independent variable (i.e., the modification of the narrative tasks), and the dependent variable (i.e., language use maturity index). The rationale underlying visual analysis in Single Case Designs is that predicted and replicated changes in a dependent variable (here as language use maturity index) are associated with active manipulation of an independent variable (the modification of the narrative tasks). When evidence for a functional effect was present, we proceeded to estimate the effect sizes using quantitative methods such as tau- $U$ and multilevel modeling.

\section{Procedures}

Our rules for conducting visual analysis involve around four steps and six variables (Parsonson \& Baer, 1978). The first step is to document a predictable baseline pattern of data entries (e.g., student is using short, truncated, and overall incoherent sentences; student does not actively use figurative language; student does not establish a claim, counterclaim, or valid reasoning; there is no evidence of comparative structures, and so on.). If a convincing baseline pattern is documented, then the second step consists of examining the data within each phase of the study to assess the within-phase pattern(s). The key question is to assess whether there are sufficient data and consistency to demonstrate a predictable pattern of responding to our treatment (e.g., does the language use maturity index reveal a change in pattern when a student is asked to write a new narrative with a modified prompt?). The third step in the visual analysis process is to compare data from each phase with the data in the adjacent (or similar) phase to assess whether manipulation of the independent variable (here in the form of three different narrative tasks) was associated with an "effect." In other words, our treatments effect will only be demonstrated if manipulation of the independent variable (the narrative tasks) is associated with predicted change in the pattern of the language maturity index. The fourth step in visual analysis is to integrate all the information from all phases of the study to determine whether there are at least three demonstrations of an effect at different points in time-i.e., documentation of a causal or functional relation. All these stages were examined for our four participants: this meets the minimum of three effects required by WWC standards (Kratochwill et al., 2013).

All of the participants' utterances were transcribed according to video transcription conventions presented in Lahey (1988). Based on these transcriptions, complex sentences produced by the participants were identified and coded. All the participant's written products were analyzed using the matrix we defined earlier (see Figure 1). All nine constituents of our proposed Language Maturity Index were detected in our participants' written products, analyzed and coded. Complex sentences were defined as sentences with two clauses (a dependent clause and an independent clause) that represent a relational effect. Complex sentences were distinguished from consecutive sentential clauses, i.e., individual sentences joined by a conjunction serving the pragmatic function of cohesion rather than representing a semantic relation. Further, the number and the length of $\mathrm{T}$ - units ${ }^{1}$ was taken to be a sign of syntactic maturity among our

\footnotetext{
${ }^{1}$ T-unit was coined by Kellog Hunt in 1965. It is defined as the "shortest grammatically allowable sentences into
} which (writing can be split) or minimally terminable unit." Often, but not always, a T-unit is a sentence. 
participants. In most instances, the context was essential in determining whether the clauses were related semantically and the nature of the relationship between clauses (i.e., content category). Moreover, each complex sentence was categorized mainly by its content and function based on Bloom and Lahey (1978) and Lahey (1988). The meaning relationships (i.e., content) of the complex sentences examined in this study were determined in one of two ways: by the matrix verb in sentences with sentential complements, or by relation between the verbs. (See Appendix A for definitions and examples of the content categories of complex sentences.) The functions of language, that is, the objectives the utterance appeared to serve for the participant, were categorized with reference to Lahey's (1998) taxonomy (see Appendix C). Additionally, as it is shown in Appendix D, 12 components were analyzed to examine figurative language use as a predictor for semantic maturity index. Let us one more time reiterate that in the data analysis process, we were not looking into the "correct" use of our proposed constituents for language use maturity index, rather, we were interested in the ways in which these productions were motivated.

\section{Results}

The visual analyses of the data indicated that there is a functional relationship between the modification of narrative tasks and the language use maturity index for all 4 participants. Thus, we proceeded to evaluate across-case effect sizes using tau- $U$ and multilevel modeling; the former was calculated by using an online calculator (Vannest, Parker, \& Gonen, 2011). Tau- $U$ is a nonparametric index of the percentage of the data that do not overlap minus the percentage of the data that overlap between the baseline phase and the treatment phases (Parker, Vannest, \& Davis, 2014). We also used multilevel modeling to estimate the effects of the modification of the narrative tasks for all the four participants and within-and betweenparticipant variability. Because measurements are nested within cases which are nested within studies, there is a multilayered and hierarchical nature to the design. For this reason, it is crucial that multilevel modeling be performed. In multilevel modeling, at least 30 measurement occasions must take place to detect large treatment effects (Ferron, Moeyaert, Van Den Noortgate, \& Beretvas, 2014). We used R Studio software to run a statistical analysis for all the 4 participants with a total of 56 measurement occasions. A significance level of $\alpha=.05$ was used for all significance tests.

\section{Visual Analysis}

In the following section, we describe the visual analyses results for each participant. In essence, Figure 2 and Table 1 are showing the same thing, the former displays it visually, and the latter presents the mean values of each phase (e.g., baseline, Treatment A, B, and C) and their effect sizes. If visual analyses indicate that a functional relationship exists between our treatment phases and the participants' language maturity index, then we discuss the effect sizes of the treatment phases. Further, we will discuss the mean, standard deviation, and effect sizes for our four participants (see Table 1). 


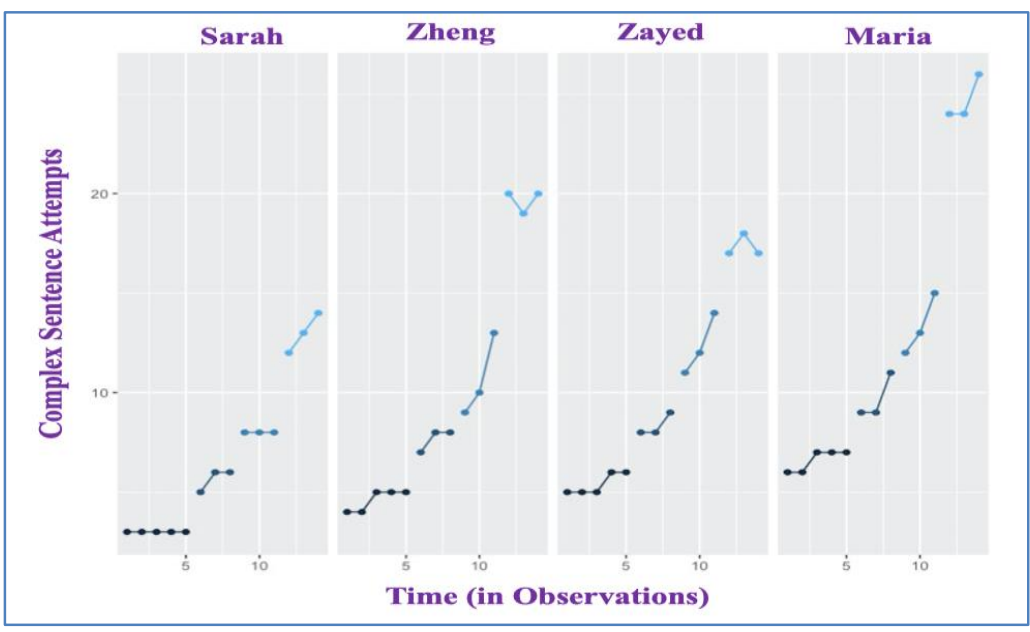

Figure 2: Visual Analysis of Use Maturity Index in the Baseline and the Three Treatment Phases for the Four Participants

Table 1: Mean, Standard Deviation, and Effect Size for all the four Participants

Effect Size type

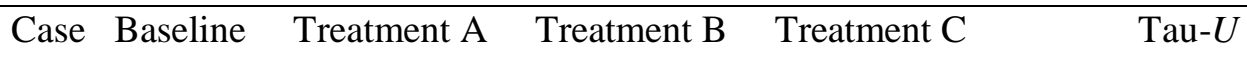

$\mathrm{M}(\mathrm{SD}) \quad \mathrm{M}(\mathrm{SD}) \quad \mathrm{M}(\mathrm{SD}) \quad \mathrm{M}(\mathrm{SD})$

$\begin{array}{lllrrr}\text { Sarah } & 3(0) & 5.6(5.77) & 8(0) & 13(1) & 1.00(\mathrm{SD}=0.33, \mathrm{Z}=3, \mathrm{P}=0.002) \\ \text { Zheng } & 4.6(0.54) & 7.7(0.577) & 10.7(2.08) & 19.7(0.577) & 1.00(\mathrm{SD}=0.33, \mathrm{Z}=3, \mathrm{P}=0.002) \\ \text { Zayed } & 5.4(0.54) & 8.3(1.15) & 12.3(1.52) & 17.3(1.15) & 1.00(\mathrm{SD}=0.33, \mathrm{Z}=3, \mathrm{P}=0.002) \\ \text { Maria } & 6.6(0.54) & 9.7(0.57) & 13.3(1.52) & 24.7(0.57) & 1.00(\mathrm{SD}=0.33, \mathrm{Z}=3, \mathrm{P}=0.002)\end{array}$

Sarah:

For the baseline phase, we looked into Sarah's five writing tasks on general topics she had already written during the course of her classes at IELP before the treatment phases started. Multiple-baseline designs need to include at least two baselines; however, in this study - to add to the internal validity of resultsfive baselines for each participant is included. Assuming other things are equal, it is preferable to have greater numbers of baselines, for it provides a greater number of replications of the effect and allows greater confidence that the observed effect in a particular time series was the result of the treatment. As 
shown in Figure 2, and the first row of Table 1, Sarah's language use maturity index during baseline was low $(M=3)$ : Short and truncated sentences and only a few additive conjunctions were detected in her writing tasks: For instance, "The sun is shining and is bright"; "It provides heat for us so we can live in this planet"; "Luckily we can extract energy from the sun so we can use less gasoline." In the baseline phase, T-units were mostly short and cohesive devices were missing: For instance: "We are dealing with a crisis. Our world is facing a big issue now." There was neither evidence of figurative language use nor comparative forms; nor was there a trend in the baseline level. Such issues were characteristic of Sarah's five writing tasks. As shown in Figure 2, and Table 1, however, Sarah's language use maturity index escalated following the treatment phases: An upward increase in language use maturity index is prevalent following treatment phases A and B. In treatment A phase, Sarah incorporated all the semantic and syntactic items that were given to her as a linguistic support to reconstruct the content of the narrative. There was no instance of figurative language use, nor comparative forms. T-units were for the most part between two to three in length in the clausal forms: For instance, "with no time to spare, Jane took a taxi"; "Jane shouted back asking the driver to get in and made him promise her to drop her in good time." What is more, Sarah's narratives during treatment A phase were the shortest in length in comparison to the other two phases (B and C). During treatment B phase, Sarah incorporated fewer words from those provided than phase A to reconstruct the content of the narrative. Again, there was no instance of figurative language use nor comparative forms. The narrative tasks she produced were longer in length in comparison to the ones she produced during treatment A phase. However, longer T-units were detected in phase B narratives: for example, "both of the drivers begin shouting out at each other and Jane screamed at them saying "stop quarrelling' but neither of them listened to her." An abrupt increase in her linguistic and pragmatic performance is noticeable following treatment $\mathrm{C}$; longer T-units were detected, for example: "lost and isolated from her community Victor, the pariah prophet, knew with certainty what was about to befall in Hokuloko but of course no one was there to believe her." Furthermore, alliteration and assonance, which are both elements of figurative language use, were detected in her narratives (e.g., "the sand dials, sun dials, moon dials, and incense clocks were all broken"). More complex sentence structures (e.g., five causal conjunctions) were identifiable in each of her photo narrative tasks as well. For pragmatic maturity index,I looked into the writer's attitude towards the reader (i.e., tone) in the narrative tasks, and noticed that she used a more solemn tone in her treatment $\mathrm{C}$ narratives: e.g., "What are the odds? A woman? A prophet? Poor, single and ugly? And who are these children? Nay, they are Xyv, Vuy and baby Co-the physical manifestation of Victor's time in past, present and future smeared by the dark forces of life. While bathing the buffalo in the river, a thunder cursed Victor to be the pariah prophet to be living with past, present and future all at the same time." This increase in language maturity index can be easily detected when we examine the mean value of each treatment phase, which were 5.6, 8, and 13 for treatments A, B, and $\mathrm{C}$ respectively. By looking at the difference in the mean value between the baseline and the three treatment phases, it is clear that the treatment has been effective overall: Tau- $U$ was calculated as 1.00 a strong effect. Tau- $U$ is considered to be a valid and precise measurement since it can be used for smallscale studies, it includes trends, and it is argued to have a strong precision power (Parker, Vannest, \& Davis, 2014). It is important to note that effect sizes from 0 to 0.31 are considered small; from 0.32 to 0.84 are considered medium; and from 0.85 to 1.0 are considered large (Parker \& Vannest, 2009). This effect was statistically significant $(\mathrm{p}<.05)$. Additionally, both Figure 2 and Table 1 show that the observed between-phase change in performance was immediate and consistent for all treatment phases. 
Zheng:

Zheng's language use maturity index during baseline phase was higher than Sarah's but still not high (M = 5.6) and almost stable: this can be explained by his higher language proficiency as indicated by his IELTS score. There was no apparent trend in the baseline level. Only a few clausal forms and a few conjunction forms (e.g., so and but) were detected during the baseline phase and the T-units were short overall. For instance, "The girl who is weeping is the one I have never met"; "Home is where your heart belongs"; "Love is an internal feeling but I cannot explain it into words"; "When you look at her eyes, you feel the sorrow"; "Her eyes are closed so she must be asleep". There was no evidence of figurative language use nor comparative forms; there was zero trend in the baseline level. This pattern was frequent in all five writing language tasks collected during the baseline phase. By looking at the results in Figure 2, and Table 1, we can see that Zheng's language use maturity index rose directly after the treatment phases started. To be more precise: after treatment A was implemented, the language use maturity index rose to $(M=7.7)$, and then it moved up to $(M=10.7)$ during treatment $B$ phase. The highest mean value for language use maturity index, for Zheng, was detected following treatment $C$ which was $(M=19.7)$. During Treatment A phase, Zheng, for the most part, incorporated all the semantic and syntactic linguistic devices that were offered to him to reconstruct the content of the narratives. He incorporated a few additive conjunctions: e.g., "physical disablement can also lead to isolation from friends and family which further creates social disengagement"; "Loneliness is a subjective feeling and emerges from deficient social relations" (my italics). There was no evidence of figurative language use nor comparative forms. During treatment B phase, Zheng used some of the synonymous constructions to reformulate the content of the narratives. His T-units were particularly longer during treatment B phase in comparison to the baseline and treatment A phase: e.g., "Such an environment can cause mental alterations where an individual may suffer from anxiety and other mental disorders that keep him away from making further social contacts and no family bonds"; "Furthermore, if an individual is suffering from physical impairment his chances of meeting people decreases which may contribute to his societal detachment." In addition, more clausal forms were prevalent in his written tasks as we moved toward treatment B phase. As shown in Figure 2, and Table 1, Zheng's language use maturity index increased during treatment $\mathrm{C}$ phase. His characters' names in his narratives were mostly ethnic (e.g., Rehman, Dr. Talukdar). He incorporated elements of figurative language such as hyperboles and metaphors (e.g., "a cloud of questions"; "gush of horror"; "daily doses of nagging"; "his aura pierced trough Rehman"). Moreover, in his narratives, he incorporated more nouns and descriptive adjectives so as to create a more picturesque sense: e.g., "Rehman knew he could never love anyone, so concepts such as loyalty, commitment, love, vows, betrayal, and hurt meant nothing but emotional waste; snarky smile." I was also able to identify elements of pragmatic maturity in his narratives during treatment $\mathrm{C}$ phase, where he maintained a more formal, dramatic, tone: e.g., "But, Dr. Talukdar instilled some form of emotional reaction in Rehman as he came closer and closer only to pause for a second and look into his eyes; Rehman quickens his feet to overcome this situation as soon as possible and as he did he saw Dr. Talukdar smiling back at him." Hence, the results of the analysis indicate that there is a functional relationship between the modification of narrative tasks and language maturity index: Tau- $U$ was 1.00 , a strong effect. This effect was statistically significant $(\mathrm{p}<.05)$. Also, Figure 2 and Table 1 show that the observed between-phase change in performance was immediate and consistent for all treatment phases. 
Zayed:

As shown in Figure 2, and Table 1, we can see that language use maturity index for Zayed was low $(\mathrm{M}=$ 4.6) during the baseline phase, but almost stable. There was no apparent trend in the baseline level. In sentential level during the baseline phase, his writings were for the most part subjective and informal: e.g., "I believe that she did the wrong act; I have to teach myself a better morality." T-units were short and only a few additive and adversative conjunctions and a few adjectives were detected during the baseline phase: e.g., "The girl cries and the other one laughs"; "The children are rude and not dressed appropriately"; "The little one is crying and is sad." There was no evidence of figurative language nor comparative forms at this phase. This pattern was frequent in all five writing tasks collected during the baseline phase. As we can see in Figure 2, during all treatment phases Zayed's linguistic and pragmatic performance improved, and the highest mean value for language use maturity index was detected during treatment $\mathrm{C}$ phase. Zayed's mean values for treatments $\mathrm{A}, \mathrm{B}$, and $\mathrm{C}$ are $8.3,12.3$, and 17.3 respectively. Very similar to our previous participants, Zayed incorporated almost all the semantic and syntactic utterances offered to him to reformulate the content of the narratives during treatment A phase. His narratives during treatment A phase were the shortest in length and the T-units were almost between 2 to 3 in length: e.g., "the government should take necessary steps to cope with climate change but sadly American President does not even recognize global warming as an issue of major concern that requires immediate attention." During treatment B phase, Zayed used a few of the synonymous constructions to reformulate the content of the narratives. As for treatment $C$ phase, use of various adjectives were detected in his narratives: e.g., "Billy and Hilly aren't conscientious warriors"; "Billy and Hilly are entitled brats." Complex sentences were more prevalent in his narratives during this phase as well: e.g., "To them freedom, democracy, and sovereignty means nothing because neither they lived a political reality of it nor did they ever read history"; "For the first time ever, Billy and Hilly realized that they can be brothers and best friends speaking the same language and eating the same pork chops for dinner every night but they are two different beings with differences." Elements of figurative language use such as hyperbole was detected (e.g., "a hotpot of disagreements"). As for pragmatic maturity, it was clear that Zayed incorporated a more formal tone by using various transitions and maintained a playful tone in his narrative. Therefore, we can see that treatment $\mathrm{C}$ has resulted in a significant growth in Zayed's language use maturity index. Hence, Tau- $U$ was calculated to be 1.00 , a strong effect. The effect was statistically significant $(\mathrm{p}<.05)$. Both Figure 2 and Table 1 indicate that the observed between-phase change in performance was immediate and consistent for all phases.

Maria:

As shown in Figure 2, and Table 1, Maria's language use maturity index during baseline phase was low $(\mathrm{M}=6.6)$ and almost stable. And there was no apparent trend in the baseline level. By looking at the results, we can detect that Maria's language use maturity index during all three treatment phases intensified. That is to say, the mean value for treatment A and B was 9.7 and 13.3 respectively. We can easily detect that treatment $\mathrm{C}$ resulted in a substantial growth in Maria's language use maturity index (M $=24.7)$. So Tau- $U$ was calculated to be 1.00 , a strong effect. This effect was statistically significant (p < .05). Also, both Figure 2, and Table 1 show that the observed between-phase change in performance was immediate and consistent for all phases. 


\section{Within-Case and Across-Case Effect Sizes: Multilevel Modelling}

Multilevel level modeling was used to estimate the effect changes of the modification of the narrative tasks on language use maturity index for all four participants and across all cases. It is important to note that the two-level model-that is, $Y_{i j}^{\prime}=\beta_{0 j}+\beta_{1 j}$ Phase $_{i j}+\beta_{2 j} D t_{i j}$, provides us more information than the single-level regression model - is preferred in this study. Accordingly, $\beta_{0 j}=\theta_{00}+u_{0 j}, \beta_{1 j}=\theta_{10}+$ $u_{1 j}$, and $\beta_{2 j}=\theta_{20}+u_{2 j}$. As Moeyaert et al. (2014, p.193) argue " $\theta 00$ indicates the average baseline level, and $\theta 10$ represents the treatment effect across the $\mathrm{J}$ cases. Each individual case, $\mathrm{j}$, can have a baseline level and a treatment effect that deviate from the average baseline level, $\theta 00$, and the average treatment effect, $\theta 10$, quantified by the participant-specific residuals ( $\mathrm{u} 0 \mathrm{j}$ and $\mathrm{u} 1 \mathrm{j}$, respectively)". Therefore, $\mathrm{R}$ was used to run the regression model, and the results are shown in table 2. Thus, table two displays: Average Baseline Level $\left(\theta_{00}\right)$, Average Treatment Effect $\left(\theta_{10}\right)$, and Average Treatment Trend $\left(\theta_{20}\right)$; estimates, standard errors, and p-values are shown.

Table 2: The estimates of the fixed effects, with the standard errors, and the P values Across the four Participants

\begin{tabular}{|c|c|c|c|}
\hline$\underline{\text { Parameter Estimated }}$ & Estimate & $\underline{\mathrm{SE}}$ & $\underline{P}$ \\
\hline Average Baseline Level $\left(\theta_{00}\right)$ & 4.48 & 0.66 & 0.00 \\
\hline Average Treatment Effect $\left(\theta_{10}\right)$ & 1.28 & 0.74 & 0.09 \\
\hline Average Treatment Trend $\left(\theta_{20}\right)$ & 1.14 & 0.34 & 0.00 \\
\hline
\end{tabular}

Now let us go over the results of Table 2: The Average Baseline Level $\left(\theta_{00}\right)$ was statistically significant $\left[\theta_{00}=4.48, \mathrm{t}(50)=6.79, \mathrm{p}<.0000\right]$ which means that during the baseline phase, the average language use maturity index of the participants can be predicted to be estimated at around 4.48. However, the Average Treatment Effect $\left(\theta_{10}\right)$, was not statistically significant $\left[\theta_{10}=1.28, \mathrm{t}(50)=1.72, \mathrm{p}=.09\right]$. What is more, we can see that the Average Treatment Trend $\left(\theta_{20}\right)$ was statistically significant $\left[\theta_{20}=1.14, \mathrm{t}(50)=3.31 \mathrm{p}\right.$ $<.0000$ ] which predicts that for one increase in one unit of time, there will be an increase in 1.14 units of language use maturity index. 
Table 3: Case-Specific Estimates of Baseline Level, Treatment Effect, and Treatment Trend across the four participants

\begin{tabular}{lllll}
\hline$\underline{\text { Parameter Estimated }}$ & $j=1$ & $j=2$ & $j=3$ & $j=4$ \\
& $\underline{\text { Sarah }}$ & $\underline{\text { Zheng }}$ & $\underline{\text { Zayed }}$ & $\underline{\text { Maria }}$ \\
Case-Specific Baseline Level $\left(\beta_{0 j}\right)$ & 3.00 & 4.47 & 4.61 & 5.83 \\
Case-Specific Treatment Effect $\left(\beta_{1 j}\right)$ & 1.47 & 1.27 & 1.30 & 1.10 \\
Case-Specific Treatment Trend $\left(\beta_{2 j}\right)$ & 0.62 & 1.19 & 1.11 & 1.65 \\
\hline
\end{tabular}

What is more, we ran the multilevel model and the results, which are the within-case baseline level $\left(\beta_{0 j}\right)$, treatment effects $\left(\beta_{1 j}\right)$, and treatment trends $\left(\beta_{2 j}\right)$, are displayed in Table 3. By looking at the first row of Table 3, we can detect that Sarah, Zheng, Zayed, and Maria's respective baseline levels $\left(\beta_{0 j}\right)$ are 3, 4.47, 4.61, 5.83. So, there was some variance between the baseline levels of the participants (see Table 2, $\sigma_{u 0}^{2}$ $=1.40$ ). This considers to be normal due to the fact that all our participants had various levels of English language proficiency, and their initial IELTS scores revealed the same fact.

For the treatment effect $\left(\beta_{1 j}\right)$, there is not that much of a variability detected (see Table $2, \sigma_{u 1}^{2}=0.05$ ). Also, when looking at the treatment trend within cases $\left(\beta_{2 j}\right)$, one can argue that it is fairly homogeneous (see Table 2, $\sigma_{u 2}^{2}=0.18$ ). Also, Table 3 shows that the lowest treatment trend was for Sarah; this is due to the fact that her language proficiency and baseline level were lower than the other participants at first place. Thus, the growth in the language use indexes can only be to a certain degree.

\section{Discussion}

Results from this study indicate that there is a functional relationship between the ways in which the narrative tasks are modified and the language use maturity index of our participants. The visual analysis and the results of Table 1 clearly demonstrate the validity of this claim. Both medium and large effect sizes were found using Tau- $U$ and multilevel modeling. The preliminary data provide evidence for language use maturity index that may be expected in specified contexts, and thus can serve as a basis for planning assessment and intervention for the ENLs.

Analysis of the baseline phase in all four participants revealed a specific pattern in language use: namely, frequent use of short and truncated sentences; short T-units (maximum two in length); minimal use of adjectives for descriptions; a small number of nouns and adjectival clauses; lack of comparative form and/or figurative language use. Likewise, the tone of the writing tasks in the baseline phase was informal and subjective. This pattern was stable and prevalent among all four participants. Furthermore, no apparent trend was observed during the baseline phase. Language use maturity index was thus at its lowest end during the baseline phase. Such linguistic behavior, it seems to me, is symptomatic of the ways in which language tasks practiced in a typical ENL/EFL classroom have been mostly focused on sentence level forms rather than the discourse level structure: hence a bottom-up rather than a holistic approach. A 
characteristic feature of the former is a disproportionate valuation of syntax at the cost of de-emphasizing semantic and pragmatic concerns.

Beginning with the treatment A phase, however, it was noted that all four participants incorporated all the semantic and syntactic linguistic devices offered to them in order to reconstruct the content of the narratives. In doing so, they incorporated a few additive and causal conjunctions. (This task was the least creative task of all the other 2 treatments and our participants did not show any creativity in reconstructing the content of the narratives.) The narratives produced for this treatment phase were the shortest in length (max. 5 to 6 sentences). So were the T-units (about two to three in length); neither comparative forms nor figurative language was detected. This pattern is emblematic of the structural limits set by the treatment A form (representing a typical writing task in EFL/ESL classes), in which the semantic and syntactic utterances offered to the learners narrow down their linguistic choices. This, in turn, reduces the possibility for linguistic creativity at semantic and syntactic level, which constitutes the main concerns of treatment B tasks.

In treatment B phase, the participants used a few of the synonymous constructions to reformulate the content of the narratives, which were longer than the ones produced during phase A. T-units were mostly two to three in length (increased in some participants in comparison to phase A). Fewer conjunctions, yet more clausal forms were used in this phase. Similar to phase A, no comparative forms nor figurative language was detected. Since participants relied on their own memory to reconstruct the content of the narrative, the narratives in this task were less descriptive, and fewer adjectives and adverbials were detected. During treatment B phase, however, the overall language use maturity index rose in comparison to the baseline phase and treatment A phase. This rise in language use maturity index of the learners can be explained by the ways in which the tasks designed for this phase provided latitude for the learners' linguistic creativity. Thus, the participants' cognitive ability was not limited as much as it was during treatment A phase. Here the learners are required to reconstruct the content of the narratives relying solely on their memory and the synonymous semantic and syntactic utterances. This then allows the learners to reflect more deeply not only on semantic and syntactic choices but also on the overall coherence of their narratives.

Treatment $\mathrm{C}$ (visual narratives) was assessed both at the macrostructure and microstructure level: At the macro-level, the visual narratives were examined from the chronological and logical organizational perspectives, the tone, and the explicitness of the narrative. At the micro-level, verbal productivity, syntactic maturity elements, semantic maturity elements were assessed. So, Treatment C (visual narrative) yielded the greatest proportion of language use maturity index: More clausal forms and longer T-units (46 in length) were detected; the use of adverbials and adjectives increased as the narratives produced in this phase were more descriptive. Elements of figurative language use (e.g., hyperbole, assonance, alliteration, metaphor) were identified as well. The narratives in this phase shifted toward a more formal and objective tone. Overall, language use maturity index escalated during this phase.

This study indicates that the use of (visual) narratives or, better still, a holistic approach to language learning results in an increase in language use maturity, where language use is understood as a balanced alteration between syntactic, semantic and pragmatic elements. The results demonstrate that real linguistic creativity appears to be a discursive phenomenon rather than a sentence level phenomenon as generative 
linguists have claimed. One of the major presuppositions of this study is that we, but more importantly, ENLs, learn holistically, not through isolated skills. In doing so, our study suggests that narrative constitutes a robust tool, for it always presupposes a specific temporal trajectory and arrangement (past, present and future). We can find concrete expressions in narrative, which implies both sequence and consequence. A temporally ordered, but also causal whole, every narrative exists on at least two levels: the level of the story and that of the act of narration. The narrative form constitutes a register in which the learner can deploy various versions of the self and see it play out its eventualities. As an order-giving structure, it endows seemingly meaningless fragments (or static images) with signification, for narrative always already presupposes a developing whole, which necessitates making connections between the parts. Thus it negates any merely unilateral (either bottom-up or top-down), fragmentary approach, but rather foregrounds the necessity for both vertical and horizontal movements, both syntagmatic and paradigmatic, both retrospective and anticipatory, both subjective and objective relations and finally both the registers of form and content. The narrative form also implies dialogue (not only between characters per se, but also between the writer and audience), which is associated with rich grammatical features like tense, modality, deixis, and clause structure. Spoken, or conversational, language tends to be in the present tense, to use short clauses, modals, and to employ 1st- and 2nd-person pronouns. We suggest that these grammatical aspects of dialogue are inescapably intertwined with literary style of narrative. Movement (development), then, rather than stasis, time rather than space, knowledge rather than information (narrative comes from the Greek gnarus meaning "to know" $[O E D]$ ) constitutes some aspects of the modality of narrative, and it is in this sense that this last must be understood as our optimum pedagogical form. Implementing narratives in classrooms can make for a culturally responsive pedagogy and it should be practiced and promoted in K-12 classrooms.

\section{Limitations and Future Directions for Research}

Although the results of this study provide evidence-based guidelines for planning assessment and intervention targeting language use maturity index, the results should be considered along with their limitations. Firstly, assessment involves the creation of a variety of tasks within our overarching narrative theme in order to identify those that facilitate, and of course, those that challenge a student's language production. In designing such tasks, one should consider the age, gender, socioeconomic status, and L1 literacy level of the student (Granger, 1996; Granger, Dagneaux, Meunier, \& Paquot, 2009; Murakami, 2013) and the content category targeted.

Secondly, in this study, the effects of narrative tasks were replicated for all our four participants with almost no variability in the effects between participants. Additional research among participants and outcomes is needed before this intervention can be considered evidence based. For instance, future research could examine if this strategy is still effective for those ENL students who have not yet established proficiency level as that of our participants.

Thirdly, while there is sufficient literature to support that a small sample size in the multilevel modeling of single-case data (Moeyaert et al., 2014) is adequate for obtaining an impartial as well as precise estimate of the fixed effects (i.e., treatment); it is important to note that interpreting between-case variance estimates needs to be carried out with great precision and attention as the results may prove to be biased. Finally, it would be stimulating to see the results of the same study after randomization is implemented. 


\section{References}

Atanassova, M. (2001). On the acquisition of temporal conjunctions in Finnish. Journal of Psycholinguistic Research, 30, 115-134.

August, D., McCardle, P., \& Shanahan, T. (2014). Developing literacy in English language learners: Findings from a review of the experimental research. School Psychology Review, 43, $490-$ 498. doi:10.17105/SPR-14-0088.1

Bachman, L. F., \& Palmer, A. S. (1996). Language testing in practice. Oxford, UK: Oxford University Press.

Baker, S., Gersten, R., \& Graham, S. (2003). Teaching expressive writing to students with learning disabilities: Research-based applications and examples. Journal of Learning Disabilities, 36, $109-123$.

Barthes, R. (1977). Image Music Text. Fontana Press.

Bloom, L., \& Lahey, M. (1978). Language development and language disorders. New York, NY: Wiley.

Canale, M. (1983). On some dimensions of language proficiency. In J. W. Oller, Jr. (Ed.), Issues in language testing research (pp. 333-342). Rowley, MA: Newbury House.

Canale, M., \& Swain, M. (1980). Theoretical bases of communicative approaches to second language teaching and testing. Applied Linguistics, 1(1), 1-47.

Cooper, T. C., Morain, G. \& Kalivoda, T. (1980). Sentence combining in second language instruction. Washington, DC: Center for Applied Linguistics.

Ehri, L. C. (1989). The development of spelling knowledge and its role in reading acquisition and reading disability. Journal of Learning Disabilities, 22(6), 356-365.

Ferron, J., Moeyaert, M., Van Den Noortgate, W., \& Beretvas, S. (2014). Estimating causal effects from multiple-baseline studies: Implications for design and analysis. Psychological Methods, 19, 493-510. doi: 10.1037/a0037038.

Gast, D. L. (2010). Single subject research methodology in behavioral sciences. New York, NY: Routledge.

Granger, S. (1996). From CA to CIA and back: an integrated approach to computerized bilingual and learner corpora. In K. Aijmer, B. Altenberg, \& M. Johansson (Eds.), Languages in contrast: text-based cross-linguistic studies. Lund studies in English: (88. pp. 37-51). Lund: Lund University Press.

Granger, S., Dagneaux, E., Meunier, F., \& Paquot, M. (2009). International corpus of learner English (Version 2.0). Louvain-la-Neuve, Belgium: Presses Universitaires de Louvain.

Halliday, M. A. K. (1989). Spoken and Written Language (Language Education). USA: Oxford University Press.

Halliday, M. A. K., \& Hasan, R. (1976). Cohesion in English, 288-289.

Hunt, K. W. (1965). Grammatical structures written at three grade levels (No. 3). Champaign, IL: National Council of Teachers of English.

Hymes (Eds.). Directions in sociolinguistics: The ethnography of communication (pp. 35- 71). New York: Holt, Rhinehart \& Winston.

Hymes, D. (1972). Models of the interaction of language and social life. In J. Gumperz \& D. In T. R. Kratochwill \& J. R. Levin (Eds.), School psychology series. Single-case intervention research: Methodological and statistical advances, (pp. 127-151). Washington, DC, US: American Psychological Association.

Isaacson, S. (1988). Assessing the writing product: Qualitative and quantitative measures. Exceptional Children, 54, 528-534.

Juel, C. (1988). Learning to read and write: A longitudinal study of 54 children from first through fourth grades. Journal of Educational Psychology, 80(4), 437-447. 
Juel, C., Griffith, P. L., \& Gough, P. B. (1985). Reading and spelling strategies of first grade children. In J. A. Niles \& R. Lalik (Eds.), Issues in literacy: A research perspective. Rochester, NY: National Reading Conference.

Kecskes, I. (2007). Formulaic language in English lingua franca. Explorations in pragmatics: Linguistic, cognitive and intercultural aspects, 1, 191-218.

Kecskes, I. (2015). How does pragmatic competence develop in bilinguals?. International Journal of Multilingualism, 12(4), 419-434.

Kecskes, I. (2016). Deliberate creativity and formulaic language use. In Pragmemes and theories of language use (pp. 3-20). Springer, Cham.

Kratochwill, T. R., Hitchcock, J., Horner, R. H., Levin, J. R., Odom, S. L., Rindskopf, D. M., \& Shadish, W. R. (2010). Single-case designs technical documentation. What works clearinghouse. Retrieved on 9 September, 2019 from https://files.eric.ed.gov/fulltext/ED510743.pdf

Lahey, M. (1988). Language disorders and language development. Needham, MA: MacMillan.

Lesaux, N., Koda, K., \& Siegel, L. (2006). Development of literacy. I: D. August \& T. Shanahan (red.). Developing Literacy in Second-Language Learners. Report of the National Panel on Language-Minority Children and Youth (s. 75-122).

Mastropieri, M. A., Scruggs, T. E., Mills, S., Irby Cerar, N., Cuenca-Sanchez, Y., Allen-Bronaugh, D., . . .Regan, K. (2009). Persuading students with emotional disabilities to write fluently. Behavioral Disorders, 35, 19-40.

Miller, J. E., Miller, J. E., \& Weinert, R. (1998). Spontaneous spoken language: Syntax and discourse. Oxford University Press on Demand.

Moeyaert, M. Ferron, J.M., Beretvas, S. N., and Van den Noortgate, W. (2014). From a single- level analysis to a multilevel analysis of single-case experimental designs. Journal of School Psychology, 52, 191-211.

Moore, B. A., \& Klingner, J. K. (2014). Considering the needs of English language learner populations: An examination of the population validity of reading in- tervention research. Journal of Learning Disabilities, 47, 391-408. doi:10.1177/0022219412466702

Murakami, A. (2013). Cross-linguistic influence on the accuracy order of 12 English grammatical morphemes. In S. Granger, G. Gilquin, \& F. Meunier (Eds.), Twenty years of learner corpus research. Looking back, moving ahead: Corpora and language in use (1. pp. 325-334). Louvain-la-Neuve, Belgium: Presses Universitaires de Louvain.

Nattinger, J. R., \& DeCarrico, J. S. (1992). Lexical phrases and language teaching. Oxford University Press.

Nowottny, W. (1962). Language poets use. Bloomsbury Publishing.

Ortega, L. (2015). Syntactic complexity in L2 writing: Progress and expansion. Journal of Second Language Writing, 29, 82-94.

Parker, R. I., \& Vannest, K. L. (2009). An improved effect size for single-case research: Nonoverlap of all pairs. Behavior Therapy, 40, 357-367.

Parker, R. I., Vannest, K. J., \& Davis, J. L. (2014). Non-overlap analysis for single-case research.

Parsonson, B., \& Baer, D. (1978). The analysis and presentation of graphic data. In T. Kratchowill (Ed.) Single Subject Research (pp. 101-166). New York: Academic Press.

Roth, F. P. (2000). Narrative writing: Development and teaching with children with writing difficulties. Topics in Language Disorders, 20(4), 15-28.

Shadish, W. R. (2013). Single-case intervention research design standards. Remedial and Special Education, 34, 26-38.

Shanahan, T. (2006). Relations among oral language, reading, and writing development. In C. A. MacArthur, S. Graham \& J. Fitzgerald (Eds.), Handbook of writing research (pp. 171-183). New York: The Guilford Press. 
Strong, W. (1985). How sentence combining works. In D.A. Daiker, A. Kerek \& M. Morenbetg: Sentence-combining: A rhetorical perspective (pp. 334-350). Carbondale, IL: Southern Illinois University Press.

U.S. Department of Education, Institute of Education Sciences, National Center for Education Statistics. (2015). National Assessment of Educational Progress (NAEP) 1990-2013 mathematics and reading assessments. Retrieved from http://www.nationsreportcard.gov/reading math 2015/\#/student-groups

Vygotsky, L. (1978). Interaction between learning and development. Readings on the development of children, 23(3), 34-41.

Weist, R. M., Atanassova, M., Wysocka, H., \& Pawlak, A. (1999). Spatial and temporal systems in child language and thought: A cross- linguistic study. A First Language, 19, 267-311.

Wray, A. (1999). Formulaic language in learners and native speakers. Language Teaching, 32(4), 213231.

\section{Appendix A. Content categories of complex sentences (based on Lahey, 1988)}

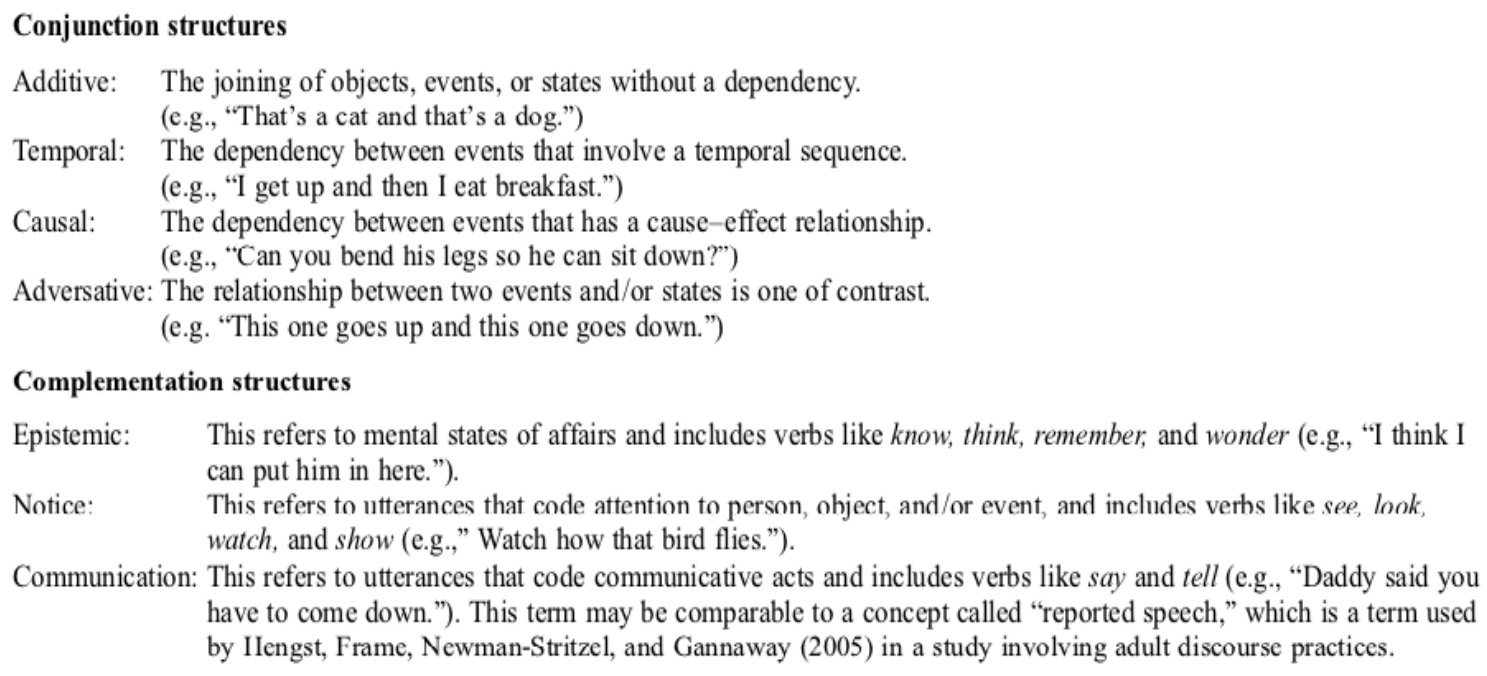

\section{Appendix B. Treatment A, B and C.}

\section{Text}

Loneliness is a subjective, negative feeling related to the person's own experience of deficient social relations. Loneliness may lead to serious health-related consequences. It is one of the 3 main factors leading to depression, and an important cause of suicide and suicide attempts. A study carried out by Hansson et al. (1987) revealed that loneliness was related to poor psychological adjustment, dissatisfaction with family and social relationships. As people grow old, the likelihood of experiencing age-related losses increases. Such losses may impede the maintenance or acquisition of desired relationships, resulting in a higher incidence of loneliness. Many people experience loneliness either as a result of living alone, a lack of close family ties, reduced connections with their culture of origin or an inability to actively participate in the local community activities. When this occurs in combination with physical disablement, demoralization and depression are common accompaniments. The death of spouse and friends and social 
disengagement after leaving work or a familiar neighborhood are some of the ubiquitous life-changing events contributing to loneliness in older people. Those in the oldest age cohort are most likely to report the highest rates of loneliness, reflecting their increased probability of such losses.

Adapted from: https://www.ncbi.nlm.nih.gov/pmc/articles/PMC3016701/

\section{Key-words for Treatment A:}

- $\quad$ subjective feeling

- deficient social relations

- lead to

- health-related consequences

- cause of suicide

- revealed that

- poor psychological adjustment

- higher incidence of loneliness

- physical disablement

- social disengagement

\section{Synonymous Constructions for Treatment B:}

- personal

- poor interpersonal skills

- cause

- mental alterations

- social contacts

- no family bonds

- incapability of joining

- a mixture of

- physical impairment

- societal detachment 


\section{Photo Narrative (Treatment C)}

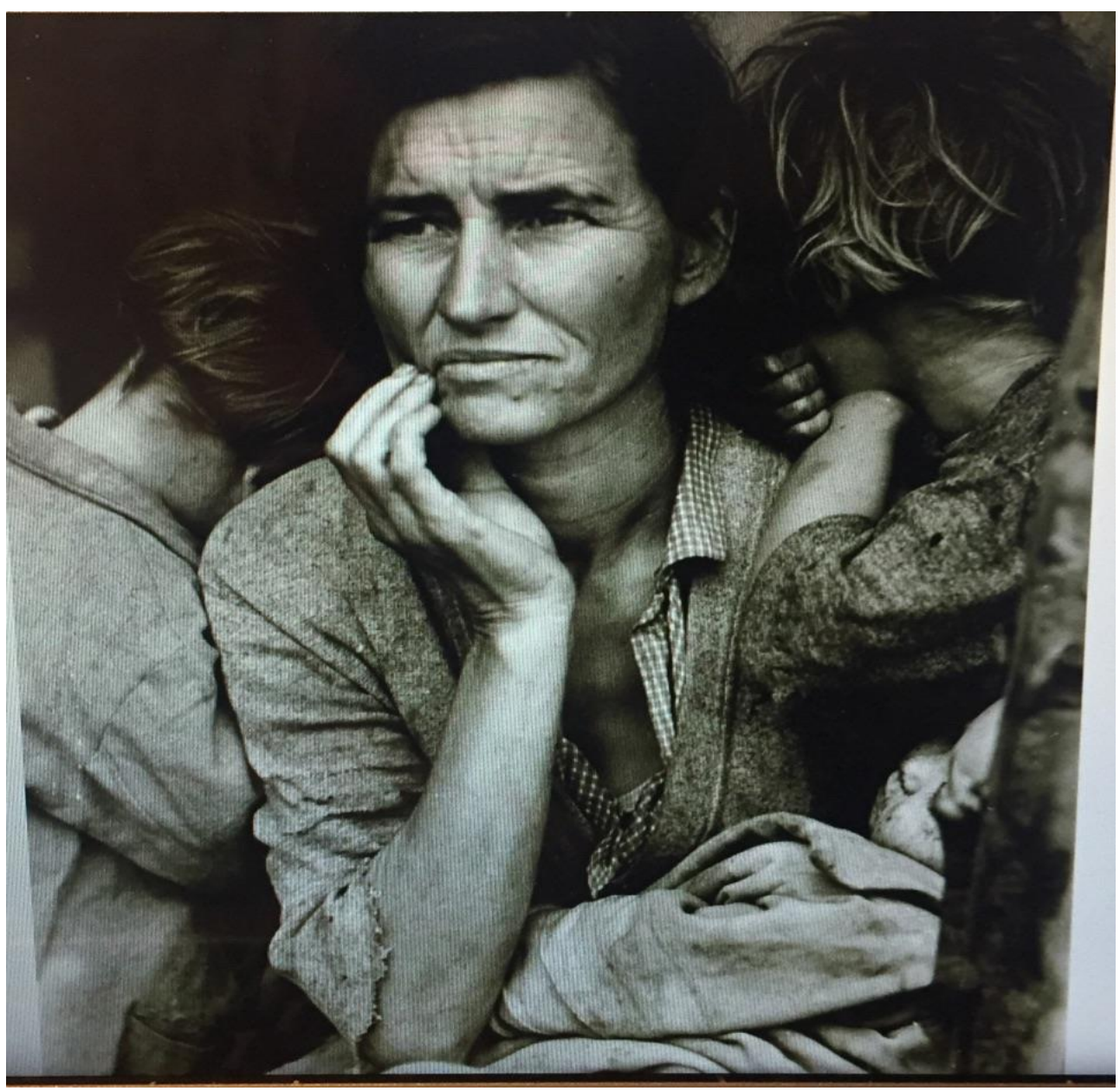

\section{Appendix C. Language Functions Examined (based on Lahey, 1988).}

Comment: Utterances that are used to describe or identify objects, people, states, and/or events with no other apparent function. Regulate: Utterances that are used to regulate others and require a response.

Request: Utterances that are used to request a specific object, event, or response.

Respond: Utterances that are a direct response to another utterance.

Routine: Utterances that consist of stereotyped utterances used in a specific setting (e.g., "He huffed and he puffed and he blew the house down."). 


\section{Appendix D. 12 categories of figurative language used for data analysis.}

\begin{tabular}{|c|c|c|}
\hline Type & Definition & Example \\
\hline Alliteration & $\begin{array}{l}\text { repeated consonant sounds at the } \\
\text { beginning of words }\end{array}$ & $\begin{array}{l}\text { "Peter Piper picked a peck } \\
\text { of purple peppers" }\end{array}$ \\
\hline Assonance & repeated vowel sounds & "How now brown cow?" \\
\hline Consonance & repeated consonant sounds in general & $\begin{array}{l}\text { The "t" sound in "Little Miss } \\
\text { Muffet sat on the tuffet." }\end{array}$ \\
\hline Hyperbole & an extreme exaggeration & $\begin{array}{l}\text { The line was a million } \\
\text { people long. }\end{array}$ \\
\hline Imagery & $\begin{array}{l}\text { concrete or abstract images that appeal } \\
\text { to the senses }\end{array}$ & $\begin{array}{l}\text { "lush, green fields;" "dark, } \\
\text { fearful night;" "bloody knife" }\end{array}$ \\
\hline Metaphor & $\begin{array}{l}\text { an implicit comparison between two or } \\
\text { more things }\end{array}$ & He was a lion of a man. \\
\hline Metonymy & $\begin{array}{l}\text { something closely related replaces the } \\
\text { thing itself }\end{array}$ & $\begin{array}{l}\text { "The crown" is used to refer } \\
\text { to the king or queen. }\end{array}$ \\
\hline Onomatopoeia & words that "sound" like what they mean & bang, crash, smash \\
\hline Personification & $\begin{array}{l}\text { giving human qualities to inanimate } \\
\text { objects }\end{array}$ & The clouds spoke. \\
\hline Simile & $\begin{array}{l}\text { a comparison between things using } \\
\text { "like" or "as" }\end{array}$ & $\begin{array}{l}\text { He was as sneaky as a } \\
\text { snake. }\end{array}$ \\
\hline Symbol & $\begin{array}{l}\text { something, often and object, that stands } \\
\text { for or represents something more abstract }\end{array}$ & $\begin{array}{l}\text { The "Statue of Liberty" } \\
\text { stands for freedom. }\end{array}$ \\
\hline Synecdoche & $\begin{array}{l}\text { a figure of speech in which a part refers } \\
\text { to the whole, or vice versa }\end{array}$ & $\begin{array}{l}\text { A single "finger is used to } \\
\text { refer to or stand for "a hand" }\end{array}$ \\
\hline
\end{tabular}

